\title{
DOE/NE ROBOTICS FOR ADVANCED REACTORS
}

\section{BIMONTHLY PROGRESS REPORT}

\section{October - November 1991}

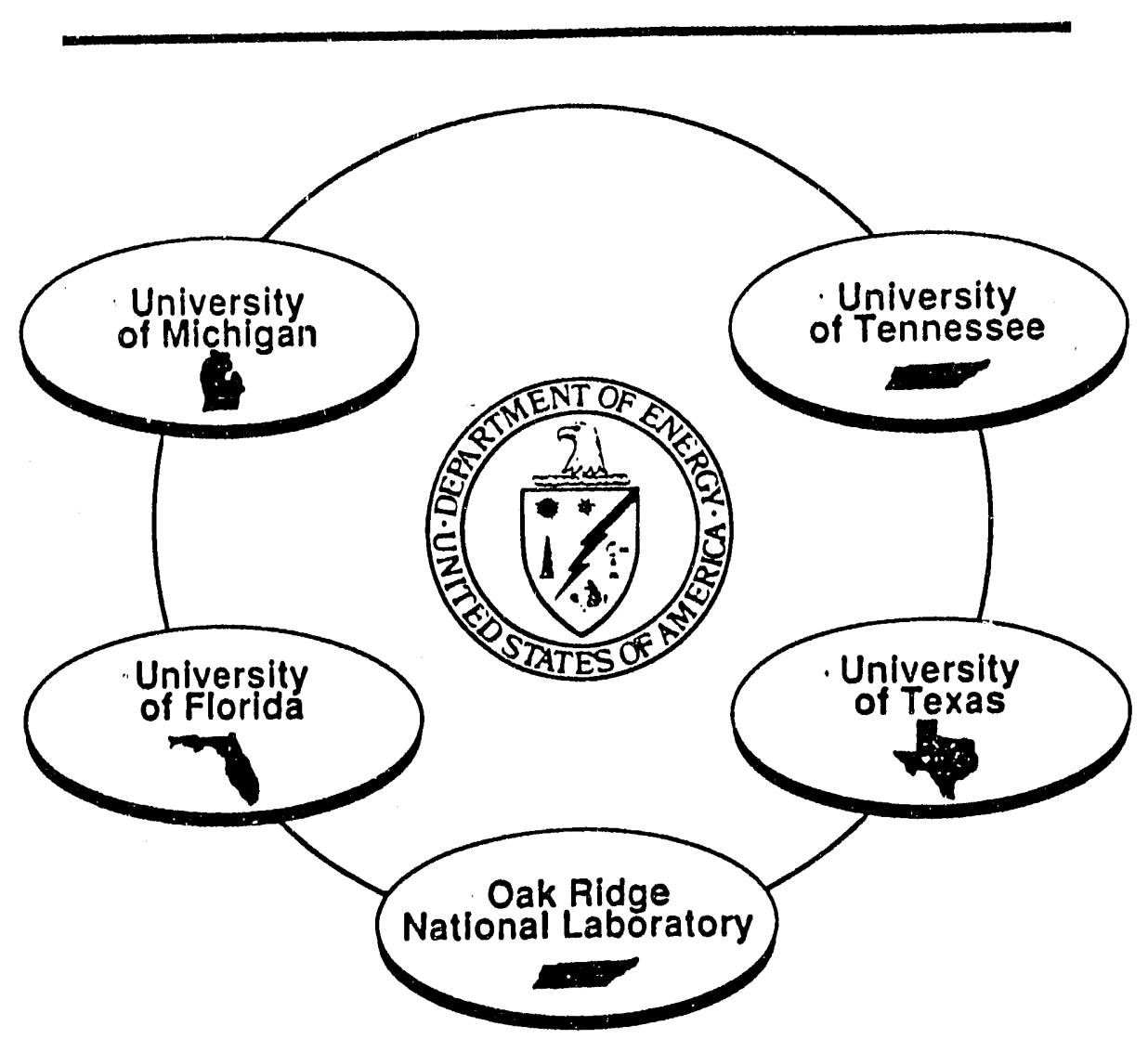

\section{DISCLAIMER}

This report was prepared as an account of work sponsored by an agency of the United States Government. Neither the United States Government nor any agency thereof, nor any of their employees, makes any warranty, express or implied, or assumes any legal liability or responsibility for the accuracy, completeness, or usefulness of any information, apparatus, product, or process disclosed, or represents that its use would not infringe privately owned rights. Reference herein to any specific commercial product, process, or service by trade name, trademaris, manufacturer, or otherwise does not necessarily constitute or imply its endorsement, recommendation, or favoring by the United States Government or any agency thereof. The views and opinions of authors expressed herein do not necessarily state or reflect those of the United States Government or any agency thereof. 


\section{Robotics for Advanced Reactors Program \\ Bi-Monthly Progress Report \\ CONTENTS}

SUMMARY

THE UNIVERSITY OF MICHIGAN . . . . . . . . . . . . . . . . 1

Significant Accomplishments and Progress Highlights .. . . . . . . 1

Reports and Major Correspondence Issued . . . . . . . . . . . . 3

Important Meetings . . . . . . . . . . . . . . . . . . . . 3

Figure 1 . . . . . . . . . . . . . . . . . . . . . . . 4

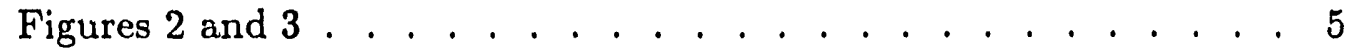

Figures 4 and 5 . . . . . . . . . . . . . . . . . . . . . . . . 6

Table $1 . . . . . . . . . . . . . . .77$

Appendix A . . . . . . . . . . . . . . . . . . . 8

THE UNIVERSITY OF FLORIDA . . . . . . . . . . . . . . . . . 12

Significant Accomplishments and Progress Highlights . . . . . . . 12

Reports and Major Correspondence Issued . . . . . . . . . . . . 14

Important Meetings . . . . . . . . . . . . . . . . . . . . . . 14

Major Problems . . . . . . . . . . . . . . . . . . . . . 14

Major Milestones . . . . . . . . . . . . . . . . . . . 14

OAK RIDGE NATIONAL LABORATORY . . . . . . . . . . . . . 15

Significant Accomplishments and Progress Highlights . . . . . . . 15

Reports and Major Correspndence Issued . . . . . . . . . . . 16

Important Meetings . . . . . . . . . . . . . . . . . . . 16

Major Problems . . . . . . . . . . . . . . . . . . 17

Major Milestones . . . . . . . . . . . . . . . . . 17

THE UNIVERSITY OF TENNESSEE . . . . . . . . . . . . . . . 18

Significant Accomplishments and Progress Highlights . . . . . . . 18

Reports and Major Correspondence Issued . . . . . . . . . . . . 20

Important Meetings . . . . . . . . . . . . . . . . . . . . 21

Major Problems . . . . . . . . . . . . . . . . . 21

Major Milestones . . . . . . . . . . . . . . . . . . 21

THE UNIVERSITY OF TEXAS . . . . . . . . . . . . . . . . . . 22

Significant Accomplishments and Progress Highlights . . . . . . . 22

Reports and Major Correspondence Issued . . . . . . . . . . . . 24

Important Meetings . . . . . . . . . . . . . . . . . . . 24

Major Problems . . . . . . . . . . . . . . . . . . . . 24

Tables 1 and 2 . . . . . . . . . . . . . . . . . . . . . 25

Table 3 . . . . . . . . . . . . . . . . . . 26 


\section{SUMMARY}

The Michigan group has developed, built, and tested a general purpose interface circuit for DC motors and encoders. This interface is based on an advanced microchip, the HCTL 1100 manufactured by Hewlett Packard. The HCTL 1100 can be programmed by a host computer in real-time, allowing sophisticated motion control for DC motors. For example, the chip can generate and supervise trapezoidal velocity profiles, and it can implement PIDtype controllers-all without the need for continuous interaction with the host computer. The developed general purpose interface is an important part of our in-house engineering infrastructure, because the interface can be used in practically any application that includes DC-motors or encoders. The interface will be made available to other members of the team.

At the University of Florida, work on modeling the details of the seismic isolators and the jack mechanism has been completed. A separate 3D solid view of the seismic isolator floor, with the full set of isolators shown in detail, has been constructed within IGRIP. A video tape has been produced showing all of the work at the University of Florida on the ALMR plus the work on the Argonne West Fuel Processing Facility.

ORNL led the robotics team at the ALMR review meeting. Discussions were held with General Electric $(\mathrm{GE})$ engineers and contractors on the robotic needs for the ALMR program. Presentations to $\mathrm{GE}$ were made by each of the team members on their research capabilities. GE agreed to visit the team member's institutions.

The Tennessee group has completed geometric modeling of the Andros Mark VI mobile platform with two fixed tracks and four articulated tracks, the five degree-of-freedom manipulator and its end-effector, and two cameras. A graphical control panel was developed which allows the user to operate the simulated robot. This simulation will help users visualize the motion and reaction of the sensor-equipped robot under various conditions.

The University of Texas team visited ORNL to complete the implementation of computedtorque controller on the CESARm manipulator. This controller was previously developed and computer simulations were carried out specifically for the CESARm robot. After upgrading the MICA software at ORNL, Phil Butler and Ross Giddings tuned the controller's feedback gains for the first four joints of the arm. Since the remaining three wrist joints are cable-driven, the computed-torque method is not implemented on the wrist in this work. A series of tests were run on the first four joints with both the computedtorque controller and a PID controller. Related data were recorded and they are currently being analyzed. 


\title{
THE UNIVERSITY OF MICHIGAN ROBOTICS FOR ADVANCED REACTORS PROGRAM
}

\author{
Bi-Monthly Progress Report \\ October - November, 1991
}

\section{Signiflcant Accomplishments and Progress Highlights:}

\section{A. General purpose low level interface for robotic motion control}

We have developed, built, and tested a general purpose interface circuit for DC motors and encoders. This interface is based on an advanced microchip, the HCTL 1100 manufactured by Hewlett Packard.

\section{Description of the HCTL 1100 chip}

The HCTL 1100 can be programmed by a host computer in real-time, allowing sophisticated motion control for DC motors. For example, the chip can generate and supervise trapezoidal velocity profiles, and it can implement PID-type controllers - all without the need for continuous interastion with the host computer. The second function of the HCTL 1100 is to read and maintain the status of incremental encoders. Here the chip determines the direction of motion, maintains a 24-bit counter, avoids hazards (a condition that can cause false readings when using encoders that generate two 90-deg phase-shifted pulse trains). At the price of $\$ 35$ per chip, the HCTL provides low cost and highly flexible engineering solutions for motion control.

\section{Summary}

We consider the developed general purpose interface an important part of our in-house engineering infrastructure, because the interface can be used in practically any application that includes DC-motors or encoders. We also would like to make this development available to other members of the DOE team, who have interest in motion control. An electronic diagram for 5-axis control expandable to 8 axis) is shown in Fig. 1; upon request from other team members we will provide a detailed description of the interface and the source code for interacting with the chip (Source code written in "C").

\section{B. Follow-up on Error Eliminating Rapid Ultrasonic Firing (EERUF)}

We believe that the ultimate test for the utility of research sponsored by DOE is whether results of this research find their way into the American industry. For this reason, we are not only publishing our work in the professional literature, but we are also directly promoting our work in industrial circles. With the successful implementation of EERUF in a demonstrable system, we were able to generate considerable interest in the commercial sector. Appendix A includes three letters from leading companies in the area of robotics, who express their interest in licensing our work on EERUF.

\section{Experiments With Using Visual Cues to Distinguish Places}

In this effort, we are attempting to develop a means to permit the robot to recognize where it is in the environment. To accomplish this, we are developing techniques in which the robot will use vision to choose a set of visual features which can be used to identify its location. We have reported on the method in earlier progress reports. In this report, we present the results of recent experiments. 
In our experiments, the robot (Figure 2) was guided through routes from one location to another in our laboratory. Figure 3 shows three routes that we guided the robot through: one long route and two short routes that intersect the long route. The routes were learned in order (i.e., route one was learned first, route two second, etc.). The goal of our experiments was to detect visual cues at each place along the route (a place is defined as an opening that leads to a new space, these are marked with capital letters in Figure 3) and use those visual cues to have the robot determine its location on future, testing runs.

The visual cues that we used were vertical edges. Figure 4 shows a typical image and the vertical edges that were extracted. The edges are stored in a grid so that their locations in the scene and their locations relative to each other are preserved. Figure 5 shows the ten grids that were constructed during training runs over the three routes. The ten grids represent one grid each at points $A, E, F$ and $G$ and two grids for points $B, C$ and $D$.

After the training runs, the robot was tested on each of the three routes. It was told to match its current location with all of the locations that it had stored during its trial runs through the three routes. Our matching algorithm is simple: for each cue in the current scene, each cell of that cue should have a corresponding cell in the stored scene that is also part of a cue of approximately the same distance (determined through stereo matching). The strength of the match is proportional to the percentage of cues that match.

Table 1 shows the experimental results. Across the top are the number of the maps stored during the training runs. Down the side are the scenes at each place during the testing run. The numbers represent the percentage of cues that matched between the current scene and the stored scene. As can be seen from this table, in six out of ten places, the correct place had the highest percentage match (i.e., the diagonal elements should be the largest). One mistaken identification was at point $B$ along route one, in this case the best match was with point $B$ along route two. This is not considered a problem. The other three mismatches all cccur in the large room (grids four, five and six created at points $C$, $D$ and $E)$. This room lacks any strong vertical edges and the robot had a great deal of difficulty determining where it was in the room. The solution to this problem is to find different visual cues that will distinguish between places in the room. Enriching the set of visual cues is the area of upcoming work.

\section{Continuing Efforts}

The Rational Reasoning System being developed has been prototyped and tested under a richer set of scenarios. We have spent considerable effort on exploring the limitations of the system, i.e., the bounds of the system in being able to produce results in reasonable, time under realistic conditions. Since the system is recursive in nature, this has been a concern for a practical implementation. We expect this work to be completed and published in the form of a doctoral thesis during January 1992.

The monocular depth recovery work based on the "hypothesize and test" approach has been thoroughly tested over the past few months. The technique has proven to be quite robust against perturbations in camera motions except for rotations about the motion axis. These results were presented at the ANS Winter Meeting, and submitted for publication to PAMI. This work is nearly complete, and has been formulated in a doctoral dissertation.

The radiation imaging work has proceeded along three lines of investigation. First, we have investigated purchasing a commercially-avajlable pan-and-tilt table for the smaller version of the radiation imaging camera. This will expedite of this device should we decide to proceed with this design. Since there is now commercial activity along these lines, we are looking at another design - diverging hole collimators with segmented detectors and 
position-sensitive photodetectors. This would permit more rapid image acquisition. It is not clear yet, however, whether the technique will work at the high energies we are designing for. We shall continue our modelling efforts over the next few months to resolve this issue. Finally, we are continuing our effort on the Compton camera design. We have now acquired and built sufficient electronics to begin testing the resolution of a limited number of the detectors (16 detectors are in the first array and 76 detectors are in the second array). This latter effort, if successful, holds the most promise for a compact, light, high spatial and energy resolution, radiation imaging device. As a result, we currently have five full time researchers pursing this effort alone. We are rushing to obtain the initial images by the end of winter.

\section{Reports and Major Correspondence Issued:}

1. Borenstein, J. and Koren, Y., "Error Eliminating Rapid Ultrasonic Firing for Mobile Robot Obstacle Avoidance," submitted for publication to the IEEE Transactions on Robotics and Automation.

2. Borenstein, J. and Koren, Y., "Noise Rejection for Ultrasonic Sensors in Mobile Robot Applications," To be presented at the IEEE Conference on Robotics and Automation, Nice, France (May 1991).

3. Y. Fuji presented our work on the Hypothesize and Test Method for monocular depth determination at the ANS Winter Meeting in San Francisco, CA.

4. N. Dogan and J. Valentine presented radiation imaging results (two papers) at the IEEE Nuclear Science Symposium in Santa Fe, NM. Both papers were also submitted for publication to the IEEE Transactions of Nuclear Science.

5. Kortenkamp, D., Baker, D., and Weymouth, T., "Using Gateways to Build a Route Map," submitted to the $1992 I E E E / R S J$ International Conference on Intelligent Robots and Systems.

\section{Important Meetings:}

J. Borenstein and L. Feng attended the Robotics and Machine Vision Show in Detroit, where they demonstrated the recently developed Error Eliminating Rapid Ultrasonic Firing (EERUF) method for reliable obstacle avoidance.

One little anecdote from this event is worthwhile mentioning here: During the show, we ran our EERUF-equipped TRC robot within a distance of only a few yards from the mobile robot at the Denning robot booth. After a short while, the Denning exhibitors asked us to not run our robot near theirs, because their ultrasonic sensor system was disturbed by our ultrasonic sensors, and their robot would run erratically. Our robot, on the other hand, was completely unaffected by th-ir sensors, because of the noise rejection feature of ERRUF. This incident demonstrated the power of the EERUF method in a convincing way, and resulted in a letter from Denning which expressed their interest in licensing the EERUF technology (see Appendix A).

Michigan (T. Weymouth) attended the LMR Review Meeting at GE San Jose, CA during this period. 


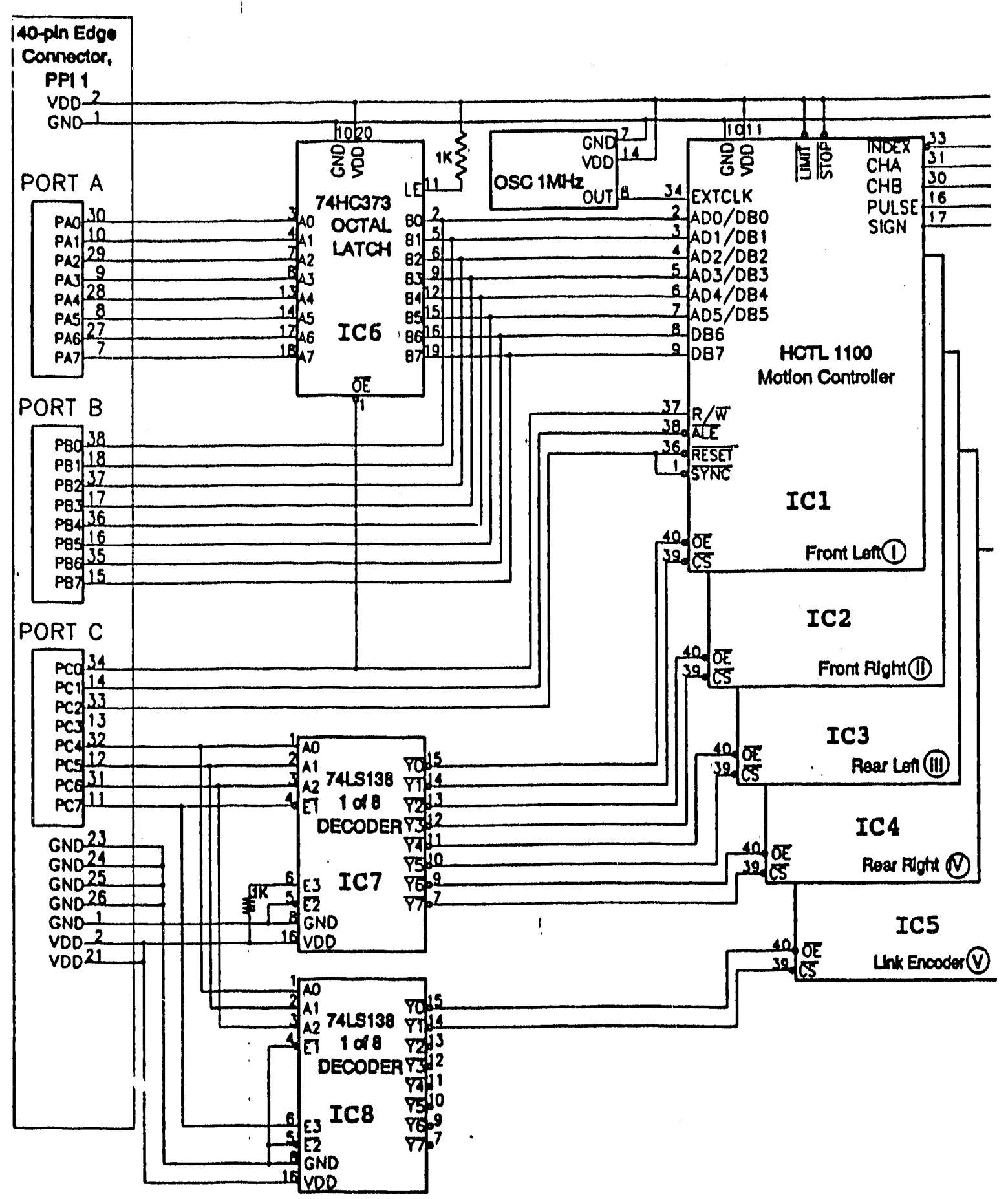

Figure 1 


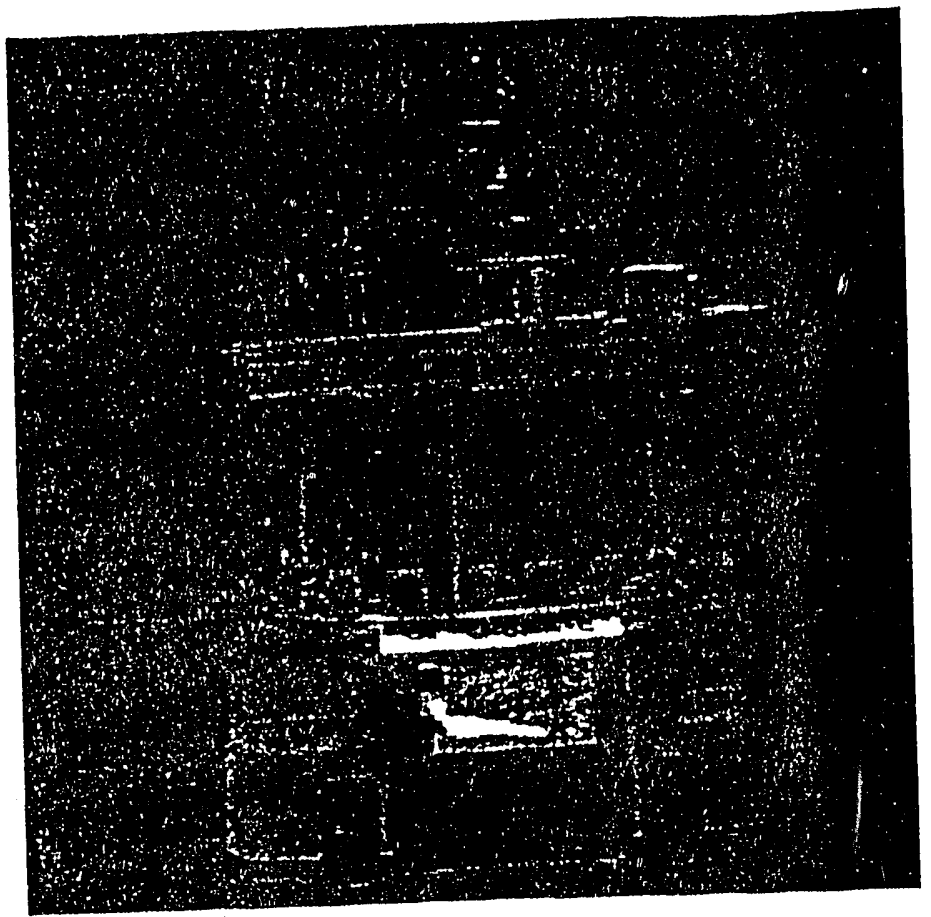

Figure 2. Slagithor, our TRC Labmate mobile platform with camera.

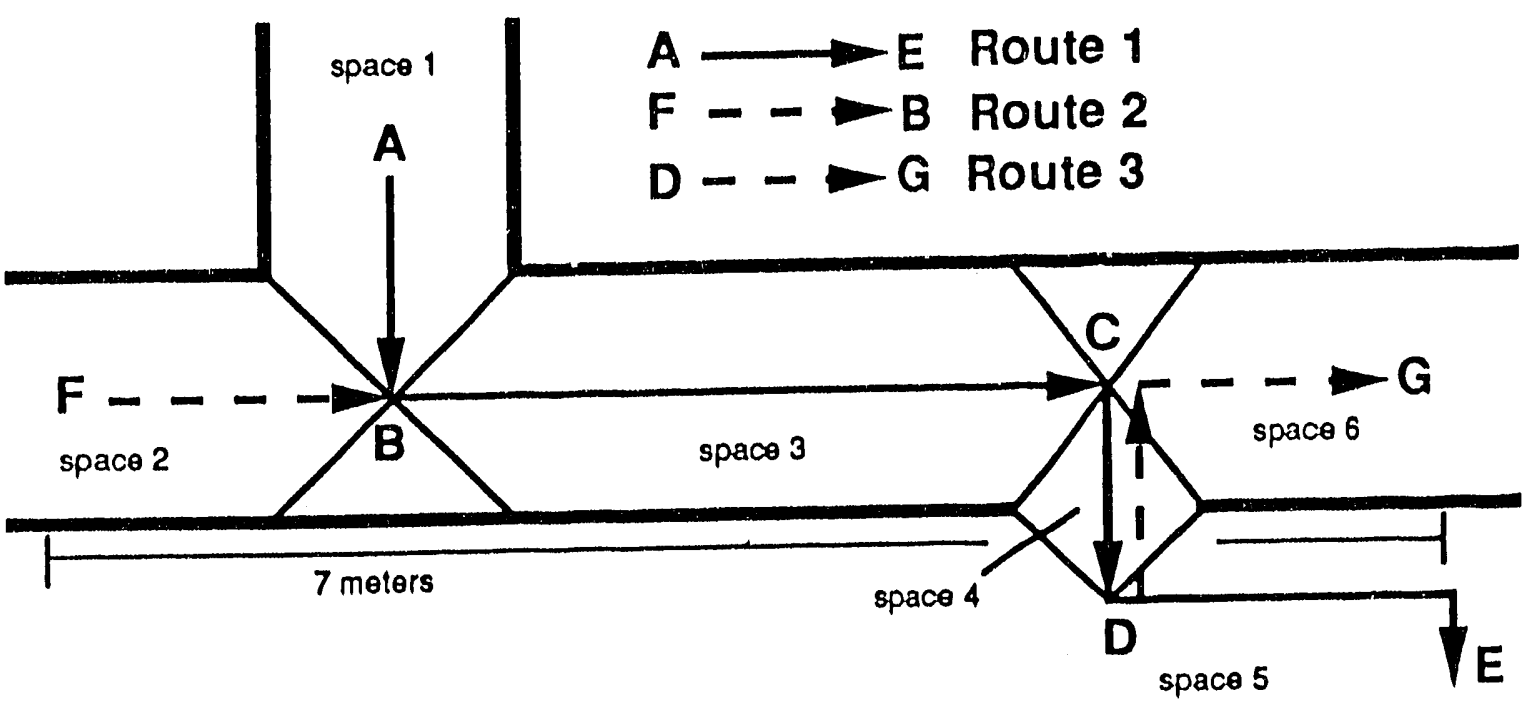

Figure 3. Our experiment space: onel long hallway that intersects with a second hallway and a door leading to a large room. Our robot was lead through three different routes, which divided the experimental space into six different sub-spaces, each with a gateway (capital letter). 

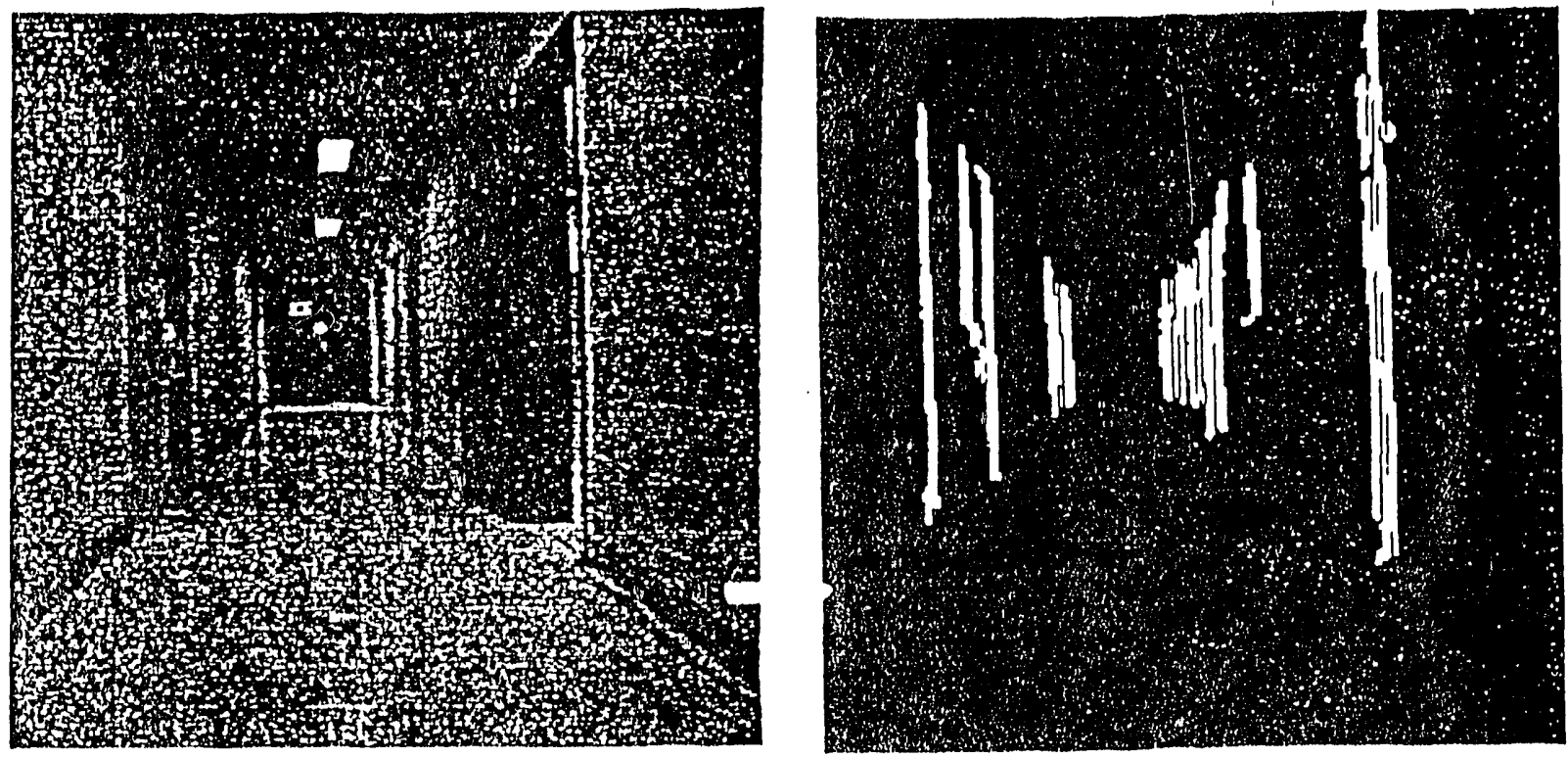

Figure 4. Left: Original image of a hallway. Right: Edge image of a hallway.

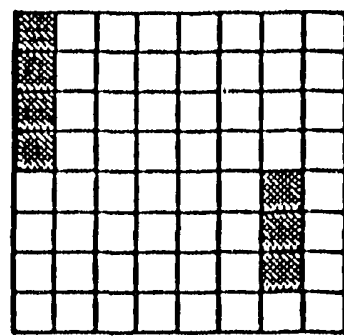

Local map 1

Point A

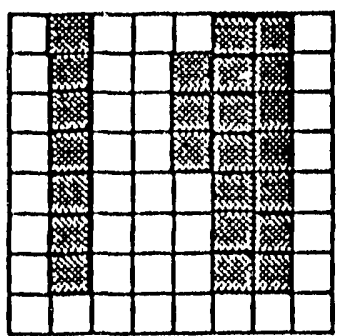

Local map 2 Point B

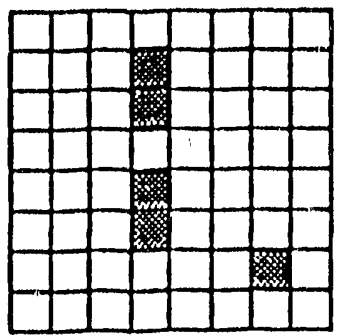

Local map 3

Point C

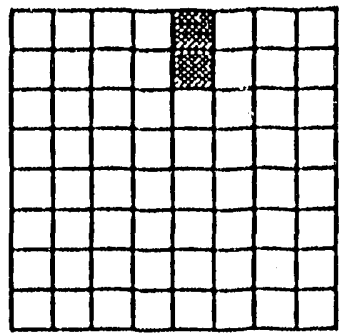

Local map 4

Point D

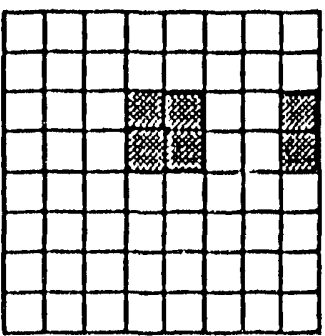

Local map 5 Point E

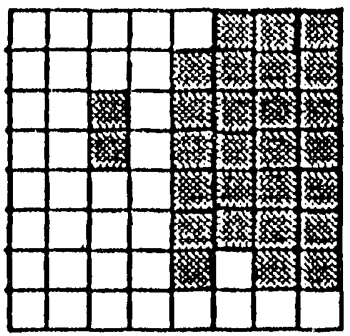

Local map 6 Point $F$

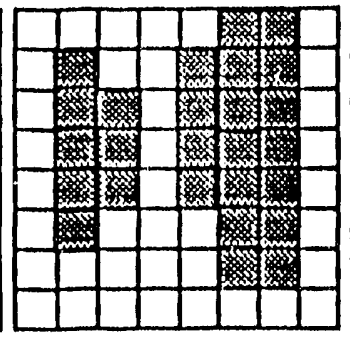

Local map 7 Point B

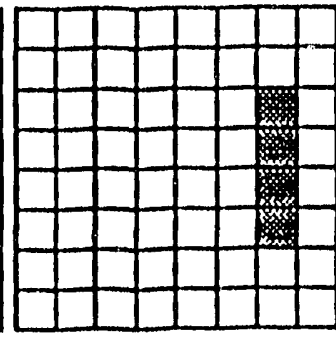

Local map 8 Point D

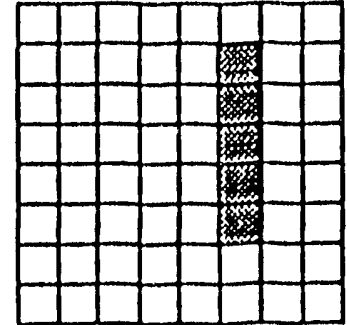

Local map 9 Point C

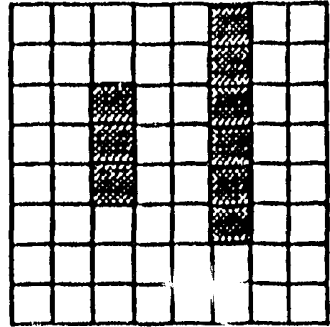

Local map 10 Point G

Figure 5. The grids of ten places (called local maps) that were encountered during the training runs. Maps one through flve are on route one, maps six and seven are on route two and maps eight through ten are on route three. 
- Table 1. Table 1 shows the results of our experiment. Across the top of Table 1 are the grids that were stored during the training runs. Down the left side of Table 1 are the current scenes encountered during the testing runs. In the hoxes are the percentage of cues that matched between the testing run's currunt scene and the stored scene.

\begin{tabular}{|c|c|c|c|c|c|c|c|c|c|c|}
\hline \multicolumn{11}{|c|}{ S.ored local maps } \\
\hline & 1 & 2 & 3 & 4 & 5 & 6 & 7 & 8 & 9 & 10 \\
\hline 1 & 100 & 0 & $\overline{0}$ & 0 & 0 & 0 & $\overline{0}$ & $\overline{0}$ & 0 & $\overline{0}$ \\
\hline 2 & 0 & 20 & 0 & 0 & 0 & 20 & 60 & 0 & 20 & 0 \\
\hline 3 & 0 & 0 & 0 & 0 & 0 & 0 & 0 & 0 & 100 & 0 \\
\hline 4 & 0 & 0 & 0 & 0 & 0 & 0 & 0 & 0 & 0 & 0 \\
\hline 5 & 0 & 0 & 0 & 0 & 0 & 0 & 0 & 0 & $\overline{0}$ & 0 \\
\hline 6 & 0 & 0 & 0 & 0 & 0 & 75 & 25 & 0 & 25 & 25 \\
\hline 7 & 0 & 75 & 0 & 0 & 0 & 0 & 100 & 0 & 25 & 0 \\
\hline 8 & 0 & 0 & 0 & 0 & 0 & 0 & 0 & 100 & 0 & 0 \\
\hline 9 & 0 & 0 & 0 & 0 & 0 & 0 & 0 & 0 & 100 & 50 \\
\hline 10 & 0 & 0 & 0 & 0 & 0 & 0 & 0 & 0 & 67 & 100 \\
\hline
\end{tabular}


Appendix A 


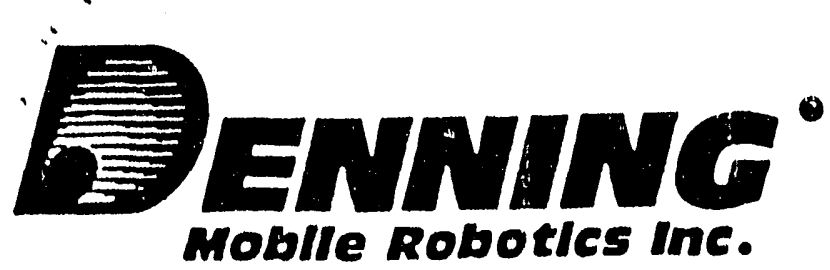

21 CONCORO STREET, WILMINOTON, MA 01887 (508) 058.7800 FAX 058.2402

Ootober 28, 2991

Dr. Johann Boranstein

The Untversity of Miohihan

Advanced Tochnology Lab

1101 Beal Avenue

Ann Arbor, MI 18109

Dear Dr. Borenstein:

Te recently saw your demonstration of Brror Bliminating Rapid oltrasonic Firing (BBROR) at the Robotics and Vision 8 how in Detroit. To are very Impressed with the performance of your system, particularly with its ability to reliably detect small objects, the high speed of obstacle avoldance, and the ability of your system to work in the presence of ultrasonic noise.

We have interest in obtaining a non-exclusive license for your technology. Please forward this letter to the Intellectual Properties office at your institute, with a request to get in touch with we in order to discuss a possible ilcensing agreement.

Yours truly,

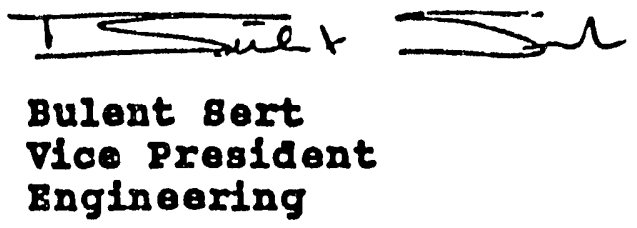

$\mathbf{b} \mathbf{8} / \mathbf{b b}$ 
October 28, 1991

Mr. Mitch Goodkin

Intellectual Properties office

$475 \mathrm{E}$. Jefferson Street

Room 2354

Ann Arbor, Michigan 48109-1248

Dear Mr. Goodkin:

As discussed in our telephone conversation, Caterpillar may be interested in licensing the ultrasonic sensing technology being developed by Dr. Johann Borenstein. A considerable amount of work remains to be done, especially cost anaiysis, befor: we can use this technology. An important step in this process is coming to agreement on a licensing arrangement.

The improved ultrasonic technology is not a core system in our product. We are successfully using commercially avallable ultrasonic systems today on our mobile robots (SGV). Dr. Borenstein's work has the potential to improve performance and reduce costs by a moderate amount. With this scenario we suggest a royalty rate of $5 \%$ of the cost of the ultrasonic sub-system for a license exclusive to our field of use. Applications of this technology to products that do not compete directiy with those of Caterpillar could provide additional licensing opportunities to you.

For this technology to be cost effective it must cost less than $\$ 400$ yielding a royalty of around $\$ 20$ per unit. Our annual production rate has been around 60 units worldwide with about a 50/50 - U.S./European split. Will this technology by patented in Europe? It is probably too early to get into too much detail, but we would suggest an annual payment based on the number of SGVs shipped to customers.

We tentatively intend to put together a plan for additional development work with Dr. Borenstein in 1992. This work will depend on coming to some up-front agreement on licensing so we ask for your thoughts on the licensing concepts defined here.

Sincerely,

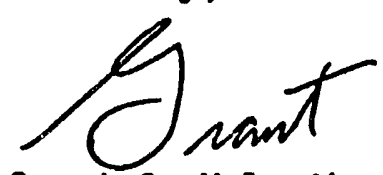

Grant C. Melocik

General Manager

Automated Vehicle Systems

216/357-2808

cc: Dr. Johann Borenstein JJHarding - CII 


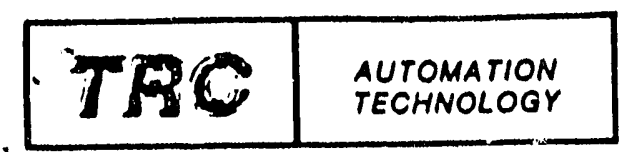

TRANSITIONS RESEARCH CORPORATION
15 GREAT PASTURE ROAD, DANBURY, CONNECTICUT 06810

(203) $798-6988$

Fax (200) 791-1082

October 21, 1991

Dr. Johann Borenstein

Head, MEAM Mobile Robotics Laboratory

Advanced Technology Laboratories

1101 Beal Avenue

Ann Arbor, MI 48109-2110

Dear Johann:

Transitions Research Corporation (TRC) develops and manufactures autonomous mobile robots for service applications, including health care delivery, floor cleaning, and research support. Our trackless robotic courier for transport in hospitals and nursing homes, HelpMate ${ }^{\mathrm{nc}}$, is used in crowded hospital corridors where safe and reliable obstacle avoidance is of the foremost importance. In the future, multiple HelpMate robots will operate simultaneously in the same environment, causing mutual disturbances in their ultrasonic sensor systems. When traveling at speeds up to $800 \mathrm{~mm} / \mathrm{sec}$, effective signal processing and noise rejection is an important requirement.

We recently reviewed a video tape from your laboratory that documented the performance of your obstacle avoidance system using the new ultrasonic firing system for rapid sampling. We were most impressed by this work and will have our Vice President for Engineering visit your lab during the next month to further discuss this system.

We have also reviewed the abstract of a proposal to NSF, entitled

"Obstacle and Collision Avoidance for Very Fast Automated Guided Vehicles," by Johann Borenstein. Our company would have the greatest interest in reliable obstacle avoidance and faster sampling of ultrasonic sensors. These and other features are provided by your system.

If successful, your proposed work for NSF will make a significant contribution to mobile robotics technology, and will help keep the United States on the leading edge of the international competition in this field. While the commercial markets are only in the early stages of developing, it is generally recognized that service robots will exceed the markets for industrial robots in the future, and the present competition in research and product development is intense.

We look forward to seeing results of your work successfully embodied in future products.

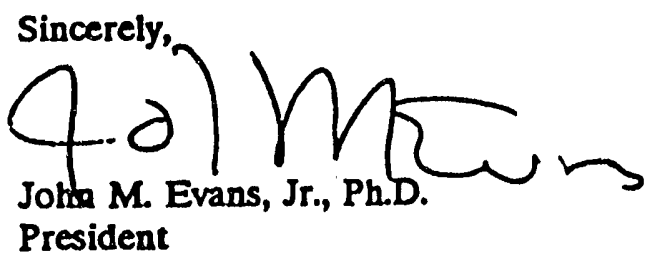




\title{
THE UNIVERSITY OF FLORIDA ROBOTICS FOR ADVANCED REACTORS PROGRAM
}

\author{
Bi-Monthly Progress Report \\ October - November, 1991
}

\section{Significant Accomplishments and Progress Highlights;}

The significant accomplishments during the reporting period just concluded were:

\section{Environmental Hardening}

Work is continuing to better understand the fundamental processes involved so that anneal processes may be effectively utilized. During the reporting period the following reports were issued (1) Radiation Hardening - Comparison of Two Approaches, (2) Protocol for Determining Failures, (3) Radiation Hardening of CMOS Devices and integrated Circuits in Nuclear Environment, and (4). The Radiation Hardness Testing on Line Monitoring Systems.

\section{Data Base Modeling}

(a) Integral Fast Reactor (IFR) Modeling

Methods have been developed within IGRIP to use analysis section to read dimensions directly from imported 2D AutoCad/IGES drawings and use these dimensions to construct 3D solid views, without ever having to extract the dimensions from IGRIP and retype then. This process is a considerable saving in both time and greatly reduced chanced for errors in transferring data from 2D to 3D.

(b) Advanced Liquid Metal Reactor (ALMR) Modeling

Work on modeling the details of the seismic isolators and the jack mechanism has been completed. A separate 3D solid view of the seismic isolator floor, with the full set of isolators shown in detail, has been constructed within IGRIP. A video tape, complete with a DOE/University of Florida Robotics Team LOGO, showing all of the work at University of Florida on the ALMR plus the work on the Argonne West Fuel Processing facility. This video was made with a special video camera that allows us to fade from black screen into and out of the various scenes and thus avoid the presence of video snow between views.

We have been able to apply the IGRIP center of gravity calculation to a series of complicated shapes of a convex nature and get answers that are verifiable by independent calculations. This has put us well on the road to easy and direct calculation of the center of gravity of the kidney been shaped cross section tube bundle, dome shaped head and piping of the sodium intermediate heat exchanged for the Advanced Liquid Metal Reactor. 


\section{ATMS Dévelopment}

(a) The first ATMS segment was assembled on 15 October. The segment consists of the ATMS body, sliding mechanism, and a pair of hydraulic cylinders. The segment has been mounted vertically in a test stand and a loading beam has been attached to simulate the loading (moments) which will exist during motion. Computer control software is being developed and

- determine the controllability of the two degree of freedom planar mechanism which represents one half of an ATMS segment,

- evaluate various sensor feedback schemes as they impact the control strategy,

- verify that the ATMS design can withstand the anticipated structural loadings.

(b) The weight of each component of an ATMS segment is as follows:

$\begin{array}{ll}\text { ATMS body } & 40 \mathrm{lbs} \\ \text { sliding mechanism (2@30 lbs.) } & 60 \mathrm{lbs} \\ \text { connecting ring } & 10 \mathrm{lbs} \\ \text { hydraulic actuators (4@30 lbs.) } & 120 \mathrm{lbs}\end{array}$

As shown, the current ATMS body weights approximaiely 40 lbs. when fabricated out of aluminum. The weight of the individual segments is the driving design factor of the ATMS. Any reduction in the individual segment weight will significantly impact the actuator sizing, actuation method, and resulting system performance. An effort was begun this reporting period to faibricate the ATMS body and sliding mechanism out of fiberglass and composites. A finite clement model of the ATMS body is being developed to verify that the maximum stresses and deflections of the composite body segment fall within acceptable limits. Initial estimations are that the ATMS body can be reduced in weight by approximately 35of this effort is to build the second ATMS segment out of fiberglass and/or composites.

(c) The development of ATMS path planning software has continued during this reporting period. A PC based program has been developed which demonstrates how the ATMS moves between horizontal planes and how it moves around or over obstacles located on each horizontal plane. The program is being transferred to run on the Silicon Graphics workstation.

\section{Man-Machine Interface}

A new method of generating true three dimensional images is being investigated. LCD technology is being examined to determine if it is possible to develop a three dimensional grid of LCD pixels. Such a three dimensional pixel grid would allow for three dimensional rendering of images which could be simultaneously viewed by multiple observers without any cumbersome headsets or goggles. 


\section{Reports and Major Correspondence Issued:}

A paper entitled "Development of a Graphical Interface for Robotic Operation in a Hazardous Environment" was presented at the IEEE International Conference on Systems, Man, and Cybernetics, October 1991.

Three papers were presented Nov. '91 American Nuclear Society meeting. The titles of the papers are:

"The Advanced Liquid Metal Reactor Modeling Project," by G. Ronald Dalton, James S. Tulenko, Haiquan Dai, and Shawn Clifford.

"Data Fusion Using Computer Graphics Work Stations," by G. Ronald Dalton.

"An On-line Annealing Process for Hardening Electronic Components in Mobile Robots for Radiation Environments," by J. S. Tulenko, D. Ekdahl, L. Utley and H. Hamilton.

\section{Important Meetings:}

R. Dalton and J. Tulenko attended the ALMR Review meeting and Project Team Meeting at San Jose, California on November 18, 19 and 20. Work scopes of interest to the ALMR project were discussed.

\section{Major Problems:}

(Explanation for Rescheduled Milestone)

The second ATMS segment was scheduled for completion at the end of December. The second segment will not now be completed until the first quarter of 1992 . The reason for this is that the second segment will now be fabricated out of fiberglass and composites rather than aluminum in order to reduce weight. No advantage was seen in fabricating another body segment out of aluminum at this time. Although the fabrication of the second ATMS segment is slightly delayed, the design and fabrication of a fiberglass/composite element has been accelerated by approximately one year.

\section{Major Milestones:}

None

\section{Projected Work for Next Reporting Period:}

The hardening work will focus on the micro aspects of the Annealing process and also on the radiation tolerance of fiber Optics, VMX Buses, and A-D Converters.

Insertion of the small 12" jacks between the two halves of the seismic isolators will be completed. The engineers at GE indicate that these are the key movers in the removal and inspection process. An animation of the removal and reinsertion process will be developed using the insights gained from the ALMR meeting in San Jose in November.

A demonstration of the center of gravity calculation of a realistic model of the sodium heat exchanger will be carried out on line. 


\title{
OAK RIDGE NATIONAL LABORATORY ROBOTICS FOR ADVANCED REACTORS PROGRAM
}

\author{
Bi-Monthly Progress Report \\ October - November, 1991
}

\section{Significant Accomplishments and Progress Highlights:}

\section{Technology Transfer}

Sweeney met with Angelo Perfumo of Ansaldo Research on October 9. ALMR robotics applications were discussed. Ansaldo is currently developing two devices with potential application to ALMR needs: a crawler robot for confined spaces, and a cutter for tubes under pressure.

ORNL is continuing to develop a cooperative effort with Public Service Electric and Gas (PSE\&G). Sweeney met with Hope Creek and Salem plant personnel on October 15 and November 18 to develop robotic maintenance task applications. A preliminary list of applications is currently under consideration. A final list of applications will be developed and prioritized. Sweeney will meet again with plant personnel in January. Sweeney, Roman, and Marian have been invited by the plant personnel to view inspection tasks during the 10 year In-Service Inspection ('jI) ai the Salem 2 plant.

On October 10 and November 21, ORNL presented research being performed under the DOE/NE Robotics Program to the director of research at Tennessee Valley Authority (TVA). A series of meetings are scheduled with TVA alternating between ORNL and Chattanooga.

On November 13, ORNL presented a paper at the American Nuclear Society (ANS) Winter Meeting on laser range camera data processing. In the Remote Systems Technology Division, about ten papers covered work involving ranging devices. This appears to be a fertile area that the robotics team has significant expertise in. Researchers at INEL and PNL are imaging underground storage tanks with the same range camera currently in use at ORNL, and the universities of Tennessee and Michigan. Information on ORNL's experience with the range camera was transmitted to researchers at INEL and PNL.

The robotics team presented five papers at the ANS meeting. Papers covered radiation hardening and detection, sensor data processing, and world modeling.

On November 18 and 19, the robotics team attended the ALMR review in San Jose. A large number of new applications for robotics were presented by the GE staff. It appears that the ALMR will need to apply robotics for inspection and maintenance if the plant design criteria for radiation exposure and availability are to be met. In addition, there are potentially a large number of robotic applications in the fuel cycle facility. The current facility is designed utilizing through-the-wall-manipulators and overhead cranes. Initial estimates of the material transfers in such a facility could be significantly enhanced by the use of robotics.

On November 20, the robotics team met with GE engineers and their contractors to discuss robotics needs for the ALMR. The team presented its current capabilities, and it was agreed that GE staff would visit the universities and ORNL starting in January. 


\section{Research}

Research is continuing under the areas of concurrent (parallel computing), sensor fusion, and laser range camera applications.

Delivery of the iWarp parallel computer is expected for February 1. Jones is revising the HELIX computer code. The file system has been rewritten, allowing the code to be transported to and installed in other computer systems more easily.

The paper "A Modular Control Architecture for Real-Time Synchronous and Asynchronous Systems," by Jones and Butler, and submitted for publication in IEEE Computer has been returned with reviewer's comments. The paper has been revised and returned to the IEEE for consideration.

\section{Program Management}

The robotics team participated in the ALMR review and discussions with GE staff on November 18, 19, and 20.

A student conference will be held at Oak Ridge, January 16-18. An agenda is being prepared.

The five year program plan is currently being prepared. University submissions to the plan were approximately five weeks overdue. Late submissions may delay publication of the plan.

\section{Reports and Major Correspondence Issued:}

None

\section{Important Meetings:}

1. October 9: Meeting with Angelo Perfumo of Ansaldo Research (ORNL) (ORNL: F. J. Sweeney).

2. October 10: TVA Information Exchange Meeting (ORNL) (ORNL: F. J. Sweeney, J. D. White, F. J. Homan; TVA: D. Wayne Hilson, E. David Daugherty).

3. October 15: PSE\& Robotics Planning Meeting (Salem, NJ) (ORNL: F. J. Sweeney; PSE\&G: Harry Roman, Frank Marian).

4. November 11-14: ANS Winter Meeting (San Francisco), CA) (ORNL: F. J. Sweeney; Univ. of Florida: J. Tulenko, R. Dalton; Univ. of Michigan: Y. Fuji).

5. November 18: PSE\&G Robotics Planning Meeting (Salem, NJ) (ORNL: F. J. Sweeney; PSE\&G: Harry Roman, Frank Marian).

6. November 18-19: ALMR Review Meeting (San Jose, CA) (ORNL: F. J. Sweeney, J. D. White; DOE: H. Alter; Univ. of Florida: J. Tulenko, R. Dalton; Univ. of Michigan: T. Weymouth; Univ. of Tennessee: M. Trivedi; Univ. of Texas: D. Tesar). 
7. November 20: Robotics Application Meeting with GE (San Jose, CA) (ORNL: F. J. Sweeney, J. D. White; DOE: H. Alter; Univ. of Florida: J. Tulenko, R. Dalton; Univ, of Michigan: T. Weymouth; Univ, of Tennessee: M. Trivedi; Univ. of Texas: D. Tesar).

8. November 21: TVA Information Exchange Meeting (Knoxville, TN) (ORNL: F. J. Sweeney, J. D. White, F. J. Homan, A. Zucker; TVA: D. Wayne Hilson, E. David Daugherty).

\section{Major Problems:}

None

Major Milestones:

1. Publish five-year program plan. (3/92)

2. Definition of a concerted experiment, draft document. (7/92)

3. Distribute enhanced version of HELIX. (9/92)

4. Computer vision library ported to iWarp computer. (9/92)

5. Demonstrate sensor fusion using range sensors. (9/92) 


\title{
THE UNJVERSITY OF TENNESSEE \\ ROBOTICS FOR ADVANCED REACTORS PROGRAM
}

\author{
Bi-Monthly Progress Report \\ October - November, 1991
}

\section{Significant Accomplishments and Progress Highlights:}

This report provides a brief summary of the research activities undertaken during the past two months.

\subsection{Sensitivity of Surface Characterization Techniques in Range Image Analysis}

(Program Plan Sections 2.2 and 9)

Range data provides valuable information about the 3-D properties of surfaces. In order to make use of this information, it is necessary to accurately characterize the surface. Many surfaces encountered in real world scenes are or can be approximated by quadrics. Least squares quadric surface fitting techniques implemented on serial processors are inherently slow. Parallel processors provide an option for increasing the speed of a surface fitting technique. Givens transformations are particularly suited for a parallel implementation of a least-squares quadric surface fitting algorithm. A communications scheme, known as cube-doubling, allows minimization of internode communications on distributed-memory hypercube parallel processors in this application.

The method used for quadric surface fitting is the least squares $Q R$ factorization. For a given quadric surface in a range image, the position of each of the pixels may be described by a complete quadratic. These equations form an overdetermined linear system. QR factorization can be used to solve for the coefficients of the quadratic. A popular method of QR factorization makes use of Givens transformations. Givens transformations lend themselves well to parallel processing, since the manipulations involved affect only two rows of the matrix at a time. Using Givens transformations, the overdetermined system of linear equations can be reduced to a 9-by-9 upper triangular matrix. A "backsolve" routine is then used to solve for the coefficients.

The need for real-time processing has resulted in the development of several types of parallel computers. The two main types of parallel computers are shared-memory and distributed-memory. Shared-memory parallel computers have several processors which share a common memory cache, while in distributed-memory computers each processor has its own memory cache. A popular design for distributed-memory computers is the hypercube. The number of processors in a hypercube is always a power of 2 , and each node is connected to those nodes whose node numbers differ by only one bit in a grey-code representation. With the high-speed processors available today, the greatest time cost with hypercubes is the internode communications. Optimizing the cost of communications is an important part of hypercube programming. The hypercube used for this research was an nCUBE/4 16-node parallel computer. In addition, a 1024 processor Intel iPSC hypercube simulator was used for algorithm development and debugging.

In order to minimize the time cost of node-to-node communications, the cube-doubling node communications scheme for a distributed-memory hypercube is used. Using this scheme, nodes talk only to immediate neighbors, avoiding the problem of having some 
nodes performing communication duties while others continue with the computational task of the algorithm.

The parallel QR algorithm divides the surface pixels among the nodes, and each node performs an initial Givens transformation for its set of pixels. The cube-doubling internode communications scheme is then used in conjunction with the Givens transformation to obtain the 9-by-9 upper-triangular matrix. At this point, a simple backsolve routine is used to take the upper-triangular matrix and solve for the coefficients. The results are then sent back to the host processor. The algorithm was developed and tested on both a hypercube simulator and an nCUBE/4 hypercube parallel computer. Significant speed-up was obtained over a strictly serial implementation of the algorithm. The images used to test the algorithm were synthetically-generated, double-precision arrays having zero noise.

Various surface patch sizes were used to evaluate the speed-ups achieved. As expected, the speed-up is affected by the size of the surface patch. For 225 pixels, for instance, the speed-up has started to level off at 16 nodes (4-D hypercube). From this, it can be inferred that the speed-up in this case would not be noticeably improved by increasing the dimension of the hypercube beyond 4. For the case of 900 pixels, however, the speed-up is still sharply rising for the 4-D hypercube, and increasing the number of nodes would still provide $\varepsilon$ significant increase in speed-up. These results support the observation that the mosic efficient hypercube size is dependent on the size of the surface patch being manipulated. It would be possible to actually begin to decrease the speed-up by increasing the hypercube dimension beyond a certain point for a certain size surface patsh.

\subsection{Simulation of Sensor-equipped Robot with Mobility and Manipulation Capabilities}

(Program Plan Section 11.1)

Robotic systems of utility in nuclear reactor environment will require mobility, manipulatory, and sensory abilities. A visualization system can be of real benefit, in the design, development and even use of such robotic systems. We are developing a visualization environment for simulation and animation of sensor-equipped robots with mobility and manipulation capabilities. The software system will help the user visualize the motion and reaction of the sensor-equipped robot under various conditions. The main goal of creating the visualization environment is to increase the efficiency of robotic system development, ensure the safety of robot operation, and reduce the cost of software and hardware development. Most of the conventional computer-graphics-based robot simulation and animation software packages lack of robot sensing simulation capability. The visualization environment has been designed to overcome this deficiency. The system has been tested by creating a simulation and animation of an Andros Mark VI mobile robot, including its sensory modalities. The system has been implemented on Silicon Graphics Personal Iris workstation and a demonstration of the system's operation has shown its utility in the simulation and animation of the sensor-equipped mobile robotic system with manipulation capabilities.

We have completed geometrical modeling of the Andros Mark VI mobile platform with two fixed tracks and four articulated tracks, the five DOF manipulator and its end-effector, and two cameras. A graphical control panel was developed which allows the user to operate the simulated Andros Mark VI mobile robot. Control options include motion (speed, forward/backward, tracks up/down, turn left/right), manipulation (open/close gripper, pick-up/put-down objects, with both forward and inverse kinematics provided for the five DOF arm), and sensing (turn cameras on/off, pan/tilt camera, and snap shot). In addition, sequences of motion, manipulation, and sensing can be recorded and played back for studies. 
This simulation and animation software system is a very useful tool for developing mobile robotic system with manipulation and sensing capabilities in various application domains. We will further enhance the system to include (1) integration of simulation and automatic task planning, (2) incorporating and utilizing sensory information feedback, and (3) creating a transformation module which makes the switching between real and simulation modes in the robotic system transparent to the user, so that duplicated programming efforts will be minimized when transferring software from simulation environment to real environment.

\subsection{Integration of Active and Passive Depth Measurement Systems in Robot Workcell}

(Program Plan Sections 2.1 and 2.2)

Autonomous systems of utility in unstructured and complex work environment may have to utilize more than one particular type of sensory mechanisms for the measurement of the 3-dimensional range (or depth) information. There are basically two types of depth measurement approaches: 1. Active, requiring an energy transmitter and a receiver, and 2. 2. Passive, which does not require an energy source but utilizes only the reflected radiation. Our research involves development of algorithms for both of these types of range sensing. Recently, we have developed a workspace characterization approach where we utilize a passive system based upon the MPH (Multi-Primitive Hierarchical) stereo analysis approach and an active system based upon the PLR (Point Laser Range) sensing approach for developing a 3-dimensional characterization of the workcell. Both of these approaches are developed $\mathrm{i}_{\mathrm{i}}$ our laboratory and we have attempted to integrate the operation of these two syste ns. We have developed the proper interface routines to use these sensors from the VAX 11-785 computer. Work is currently underway to develop a set of display and evaluation functions for performing a detailed comparative analysis of the integrated "active-passive" depth measurement system.

\section{Reports and Major Correspondence Issued:}

1. H. B. Gadagkar and M. M. Trivedi, "Active Exploration of a Robotic Workcell," proceedings of the IEEE International Conference on Systems, Man, and Cybernetics, Charlottesville, VA, October 1991.

2. J. C. Sluder and M. A. Abidi, "Parallel Image Data Processing: A Real Case Study," Proceedings of Intelligent Robots and Computer Vision X, Boston, November 14-15 1991 .

3. C. Chen and M. M. Trivedi, "Simulation and Animation of Sensor-Based Robots for Virtual and Real-World Applications," Presentation at the Workshop on Intelligent Robotic Systems: Design and Applications, Boston, November 14, 1991.

4. S. Marapane and Y. Roth, "India Robotics Symposium Addressed Regional and Global Concerns," Optical Engineering Reports, No. 95, November 1991, pp. 12-13. Also appeared in IEEE Robotics and Automation Newsletter, September 1991. 


\section{- Important Meetings:}

1. IEEE International Systems, Man, and Cybernetics Conference, Charlottesville, VA, October 13-16, 1991. Attended by Gadagkar and Trivedi. Trivedi presented a tutorial on Computer Vision and participated in a panel discussion on Future Research Directions. Gadagkar preser ted a paper.

2. Workshop on Intelligent Robotic Systervs: Design and Applications, Boston, November 14, 1991. Attended by Chen, Marapane, Sluder and Trivedi. Trivedi served as the Chairman of the Workshop. Chen presented a talk.

3. Symposium on Intelligent Rへbotic Systems, Boston, November 13-15, 1991. Attended by Abidi, Chen, Marapane, Sluder and Trivedi.

4. ALMR Review Meeting, General Electric, Corp., San Jose, November 18-19, 1991. Attended by Trivedi.

5. Robotics for Advanced Reactors Consortium Meeting with the ALMR Technical Team, General Electric Corp., San Jose, November 20, 1991. Talks given by the five PIs. Trivedi presented the University of Tennessee's research overview.

\section{Major Problems:}

None.

\section{Major Milestones:}

Our research efforts are directed towards accomplishing the following objectives in the next two months:

1. Feature Selection for Range and Intensity Data itusion - (Program Plan Sections 2.2 and 8.1)

2. Active Exploration of Robotic Workcell using Contact and Non-Contact Sensors. - (Program Plan Sections 2.1, 2.2, 2.4 and 8.1)

3. Evaluation of Range-based Motion Measurements. - (Program Plan Section 2.2) 


\title{
THE UNIVERSITY OF TEXAS \\ ROBOTICS FOR ADVANCED REACTORS PROGRAM
}

\author{
Bi-Monthly Progress Report \\ October - November, 1991
}

\section{Significant Accomplishments and Progress Highlights:}

Report on Actuator Development

Previous developments in the actuator project are published in a report. This report first lists the requirements and then reviews the components and various design alternatives. Later, design, machining and assembly of the first prototype actuator module is presented in detail. Initial test results and a comparison of the prototype actuator performance to existing commercial systems are reviewed. The contents of this report includes the following:

Design of the Actuator Module

- An Idealized Actuator

- Functions and Specifications

Global Functions

- Selecting Components

- Electrical Power

- Mechanical Power

- Contrul

- Sensing

- Structure

Functional Mechanical Components

- Gears

- Brakes

- Bearings

- Seals

Machining and Assembly

- Machining of Structural Components

- Purchasing of Selected Items

- Assembly of the Actuator

\section{Performance Comparison}

- Actual Performance Specifications of the Actuator Prototype

- Performance of Similar Actuators

Appendices

- Layout Development Drawings

- Actuator Parameters List

- Actuator Parts List

- Principal Machining Drawings

- Implementing Actuator Control Using IGBT Transistors 
- Developing Mechanical Design Procedure for Lightweight Stiff Actuator Module

- Structural Design of a Two-Degree-of-Freedom Knuckle for Modular Robots

- Epicyclic Gear Train Design for the Actuator Module

- Structural Design of a One-Degree-of-Freedom Elbow for Modular Robots

- Electric Prime Mover Technology for Robot Actuators

\section{Controller Algorithms Tested on CESARm}

Between November 12 and 15, Ross Giddings visited ORNL to complete the implementation of computed-torque controller on the CESARm manipulator. This controller was previously developed and computer simulations were carried out specifically for the CESARm robot. After upgrading the MICA software at ORNL, Phil Butler and Ross Giddings tuned the controller's feedback gains for the first four joints of the arm. Since the remaining three wrist joints are cable-driven, the computed-torque method is not implemented on the wrist in this work. A series of tests were run on the first four joints with both the computed-torque controller and a PID controller. Related data were recorded and they are currently being analyzed.

\section{Real-Time Inverse Kinematics for Redundant Arms}

Within the past two years, the Texas team has developed software to build modular robots. This software first offers a menu of modules to construct a robot, later allows the user to animate the robot by directly changing its joint displacements. Although these steps were necessary, now the program needs to accept end-effector's path (specified by the user), find the corresponding joint displacements and then animate the robot movements. In other words, a processor is necessary to map the end-effector space into the joint space before the animation takes place. This is a challenging problem for an n-link, general robot, since an over-constrained robot may not be able to take the required end-effector position. A sixlink robot, for example, may run into a singularity position in which joint displacements can not be determined. Or, a redundant arm with more than six links may have infinitely many joint positions all satisfying the specified end-effector position. In such a case, the solution lies in the selection of the best joint positioning. Depending on the task and priorities, one may wish to position the joints so that obstacles in the workspace are avoided. This extra condition one can specify to improve system performance is called performance index or cost function. Since closed-form solution to this problem can not be usually obtained, numerical methods are often used. However, finding solutions numerically tends to slow down the process, and finding the joint positions in real time may even become impossible as the number of links increases.

Currently, a four degree-of-freedom robot has been constructed using the modular software developed before. Only the end-effector positioning is specified, and the remaining one degree-of-freedom represented the redundancy for this arm and is used to find an optimal solution. So far, a performance index is used to avoid joint limitations. Since this was a four degree-of-freedom arm, real-time solutions obtained were fast enough, and animation on the computer was not affected adversely. As mentioned above, this will become a serious problem as more complicated robots and performance indices are used.

Structural Design of Knuckle Modules Providing Two Degrees of Freedom

In continuing on the design of knuckle modules, actuators from several companies were compared to determine approximate dimensions for given actuator output torques. The length and diameter of the actuators were used to calculate actuator volume. The volume (and weight) was then graphed with respect to torque. In this way, the volume and weight 
of an actuator was estimated for a given torque. A similar analysis was done to examine gearheads which utilize Ferg'sson's paradox. Since gearhead volume depends upon both the input torque and the gear ratio, a three dimensional graph was required.

Three different actuator torques from the lower, middle and upper range of the surveyed actuators were chosen. Once an actuator torque was chosen, the actuator volume and weight were estimated (see Table 1). Determining the gearhead parameters was slightly more complex. By using the actuator torque as an input torque, along with a specified gear ratio, the gearhead volume was estimated. Four gear ratios from the lower to the upper ranges were picked $(40,100,160$, and 220 to 1$)$. These ratios yielded four different gearhead volumes for each input torque. The gearhead volume was used to estimate the output torque which in turn was used to estimate the gearhead weight (see Table 1).

Combining the information from the actuators and the gearheads, complete drive units were formed. The output torque of the drive unit is equal to the output torque of the gearhead. The total weight and volume of the drive unit are simply the weight and volume of the actuator and the gearhead added together. Different combinations of actuators and gearheads can produce the same output torque. However, choosing a smaller actuator coupled to a gearhead with a larger gear ratio reduced the weight and volume of the drive unit. Therefore, the actuators combined with gear ratios of 220: 1 (shown in bold in Table 1) produced the optimal drive units.

For a given drive unit volume a reasonable length and diameter were chosen. The ratio of the diameter to the length of an actuator is fairly arbitrary. Gearheads using Ferguson's paradox, however, have a much more specific relationship between their diameter and length. For the optimal gearhead volumes $\left(112,327\right.$, and $\left.563 \mathrm{in}^{3}\right)$ the ratios of diameter to volume were $2.8,3.0$ and 3.0 . By specifying a constant diameter to volume ratio of 3.0 for all three gearheads, their diameters and lengths were calculated. By requiring the actuator diameter to be equal to the gearhead diameter, the actuator dimensions were also calculated (see Table 2). Combining the data in Table 2, the dimensions of the three optimal drive units were calculated (see Table 3 ). Table 3 provides a reasonable estimate for the parameters of three drive unit sizes.

\section{Reports and Major Correspondence Issued:}

The University of Texas group published the following report:

"Design and Prototype Development of Robot Actuator Modules," by J. Iaconis et al.

A copy of this report will soon be transmitted to ORNL.

\section{Important Meetings:}

Ross Giddings was at ORNL on November 12-15. He worked with Phil Butler to implement previously developed controllers on the CESARm manipulator.

\section{Major Problems:}

None. 
Table 1. Actuator and Gearhead Combinations

\begin{tabular}{|c|c|c|c|c|c|c|c|c|}
\hline \multicolumn{3}{|c|}{ Actuator } & \multicolumn{4}{|c|}{ Gearhead } & \multicolumn{2}{|c|}{ Total } \\
\hline $\begin{array}{l}\text { Torque } \\
\text { (in Ib) }\end{array}$ & \begin{tabular}{|c|}
$\begin{array}{c}\text { Volume } \\
\left(\text { in }^{3}\right)\end{array}$ \\
\end{tabular} & $\begin{array}{l}\text { Weight } \\
\text { (b) }\end{array}$ & Ratio & $\begin{array}{c}\begin{array}{c}\text { Volume } \\
\left(\text { in }^{3}\right)\end{array} \\
\end{array}$ & $\begin{array}{l}\text { Output } \\
\text { Torque } \\
\text { (in lb) }\end{array}$ & $\begin{array}{l}\text { Weight } \\
\text { (lb) }\end{array}$ & \begin{tabular}{c|} 
Total \\
Weight \\
(lb) \\
\end{tabular} & \begin{tabular}{|c|} 
Total \\
Volume \\
(in $\left.{ }^{3}\right)$
\end{tabular} \\
\hline \multirow[t]{4}{*}{50} & \multirow[t]{4}{*}{150} & \multirow[t]{4}{*}{27} & 40 & 35 & 125 & 5 & 32 & 185 \\
\hline & & & 100 & 63 & 500 & 9 & 36 & 213 \\
\hline & & & 160 & 90 & 950 & 17 & 44 & 240 \\
\hline & & & 220 & 112 & 1350 & 21 & 48 & 262 \\
\hline \multirow[t]{4}{*}{150} & \multirow[t]{4}{*}{330} & \multirow[t]{4}{*}{56} & 40 & 90 & 950 & 17 & 73 & 420 \\
\hline & & & 100 & 163 & 2200 & 30 & 86. & 493 \\
\hline & & & 160 & 250 & 3600 & 42 & 98 & 580 \\
\hline & & & 220 & 327 & 4850 & 57 & 113 & 657 \\
\hline \multirow[t]{4}{*}{250} & \multirow[t]{4}{*}{440} & \multirow[t]{4}{*}{71} & 40 & 165 & 2250 & 30 & 101 & 605 \\
\hline & & & 100 & 252 & 3650 & 43 & 114 & 692 \\
\hline & & & 160 & 437 & 6600 & 79 & 150 & 877 \\
\hline & & & 220 & 563 & 8700 & 102 & 173 & 1003 \\
\hline
\end{tabular}

Table 2. Actuator and Gearhead Dimensions

\begin{tabular}{|c|c|c|c|c|c|}
\hline \multicolumn{3}{|c|}{ Gearhead } & \multicolumn{3}{c|}{ Actuator } \\
\hline $\begin{array}{c}\text { Volume } \\
\left.\text { (in }{ }^{3}\right)\end{array}$ & $\begin{array}{c}\text { Diameter } \\
\text { (in) }\end{array}$ & $\begin{array}{c}\text { Length } \\
\text { (in) }\end{array}$ & $\begin{array}{c}\text { Volume } \\
\text { (in }{ }^{3}\end{array}$ & $\begin{array}{c}\text { Diameter } \\
\text { (in) }\end{array}$ & $\begin{array}{c}\text { Length } \\
\text { (in) }\end{array}$ \\
\hline 112 & 7.53 & 2.51 & 150 & 7.53 & 3.37 \\
\hline 327 & 10.77 & 3.59 & 330 & 10.77 & 3.62 \\
\hline 563 & 12.91 & 4.30 & 440 & 12.91 & 3.36 \\
\hline
\end{tabular}


Table 3. Drive Unit Parameters

\begin{tabular}{|c|c|c|c|c|}
\hline Size & $\begin{array}{c}\text { Output Torque } \\
\text { (in lb) }\end{array}$ & $\begin{array}{c}\text { Weight } \\
\text { (b) }\end{array}$ & $\begin{array}{c}\text { Diameter } \\
\text { (in) }\end{array}$ & $\begin{array}{c}\text { Length } \\
\text { (in) }\end{array}$ \\
\hline Small & 1350 & 48 & 7.53 & 5.88 \\
\hline Medium & 4850 & 113 & 10.77 & 7.21 \\
\hline Large & 8700 & 173 & 12.91 & 7.66 \\
\hline
\end{tabular}


OAK RIDGE NATIONAL LABORATORY

OPEAATED BY MARTIN MARIETTA ENEROY SYSTEMS. INC.

FOA THE U.S. DEPARTMENT OF ENEAGY
POST OFFICE BOX 2008

OAK RIDGE, TENNESSEE 37831

December 17, 1991

Mr. Harry Alter

Office of Advanced Reactor Programs

NE-452

U.S. Department of Energy

Washington, D. C. 20545

Dear Harry:

Bimonthly Progress Report - DOE/NE Program in Robotics for Advanced Reactors

Enclosed is a summary report, as well as the bimonthly reports (October - November 1991) by the four university groups and Oak Ridge National Laboratory.

Sincerely yours,

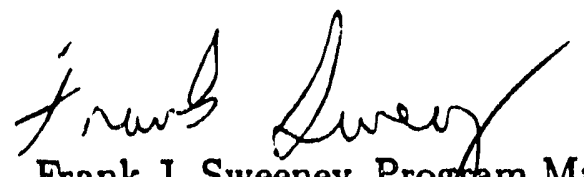

Frank J. Sweeney, Progfam Manager

Robotics for Advanced Reactors

FJS:alh

Enclosure

Bimonthly Progress Report

cc/enc: Distribution Attached 

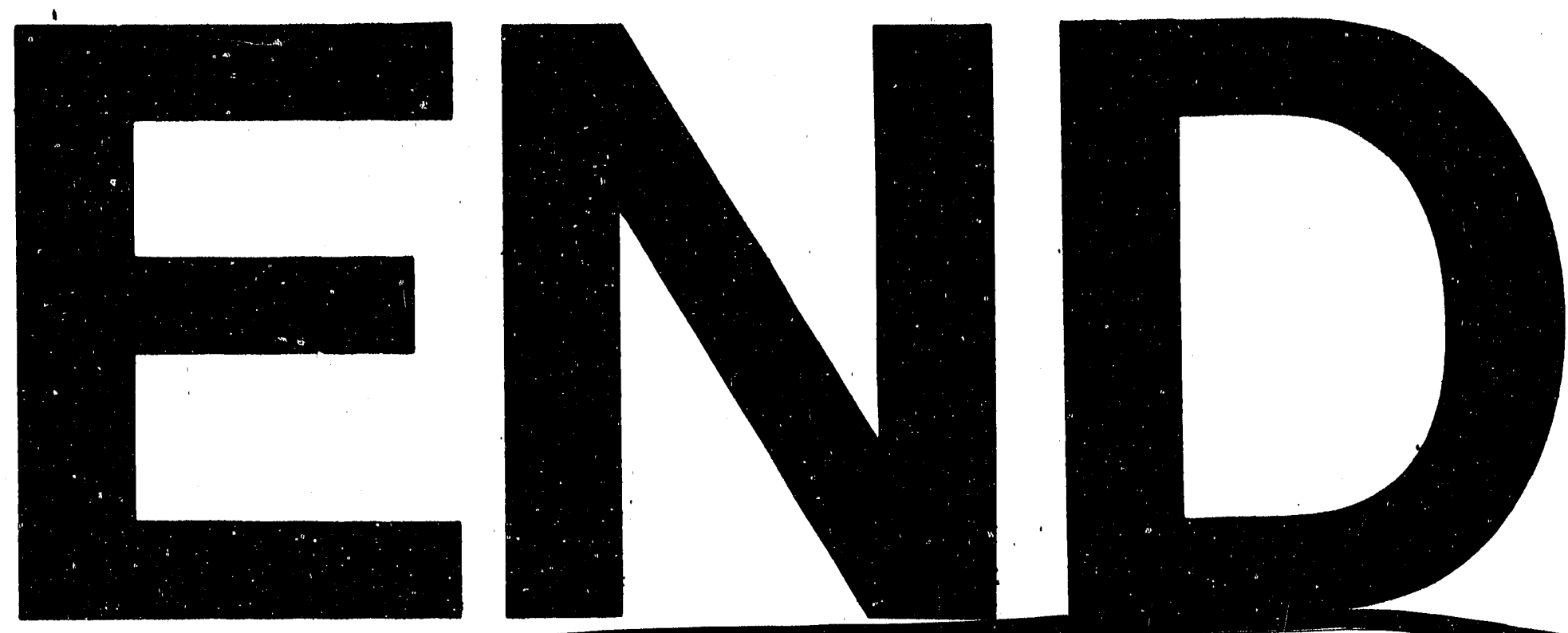

$\because$

7

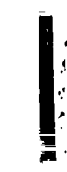
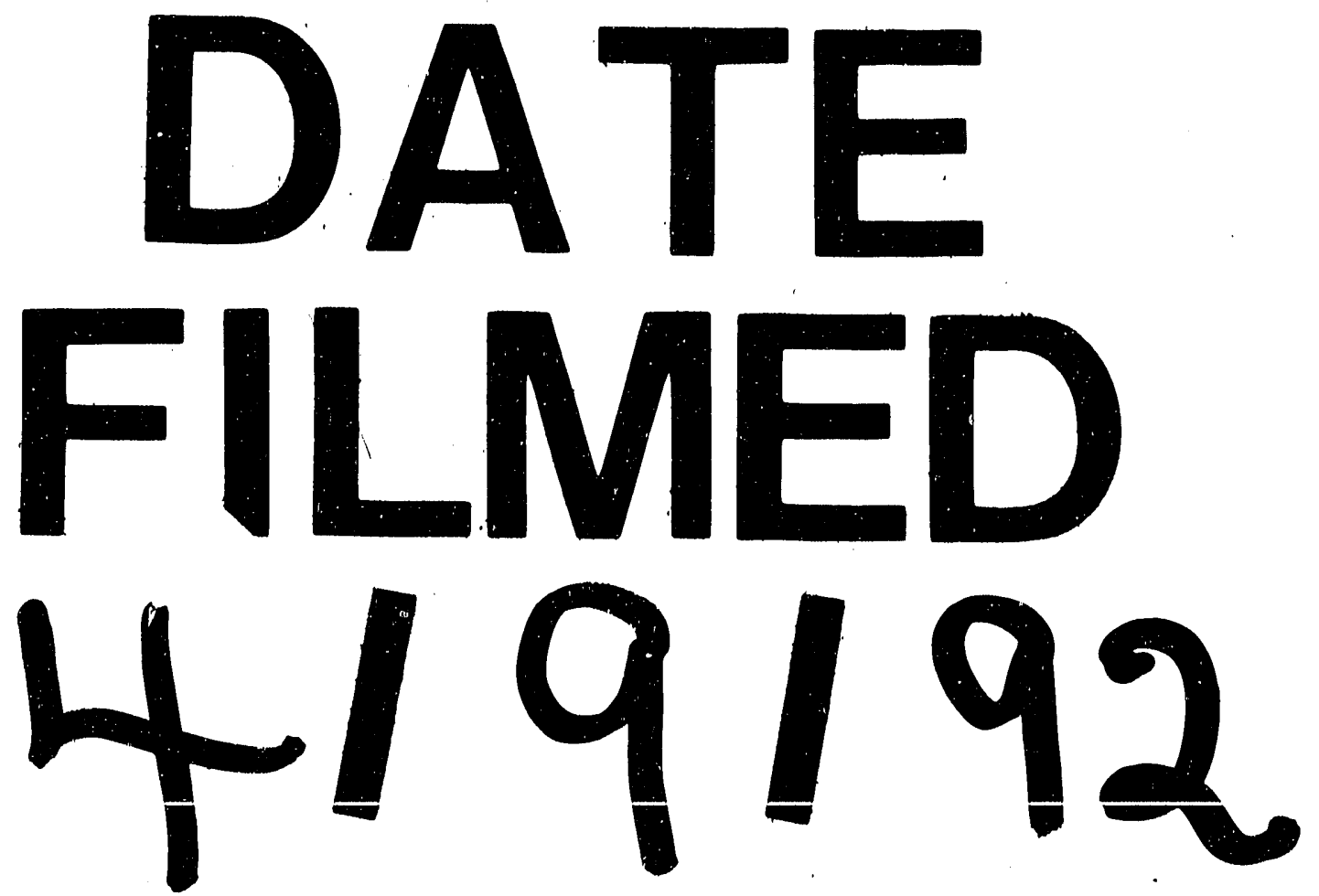

$z$ 


\section{-}

$\mid$ 